\title{
Pancreatic Neuroendocrine Tumor pNX TNM Finding v8
}

National Cancer Institute

\section{Source}

National Cancer Institute. Pancreatic Neuroendocrine Tumor pNX TNM Finding v8. NCI

Thesaurus. Code C135557.

Pancreatic neuroendocrine tumor in which the regional lymph nodes cannot be assessed.

(from AJCC 8th Ed.) 